\section{Effect of malaria on the out- comes of sickle cell phenotypes in a semi-nomadic population}

Baffa A. Gwaram, Mahmood M. Dalhat, Muhammad Hamza, Zaiyad G Habib, Musa M. Bello, Ahmad M. Yakasai,

Aisha H. Sadauki, Hauwa Aliyu, Zira G. Vandi, Faruk Sarkin-Fada, Kamilu M. Karaye, Abdulrazaq G. Habib

Bayero University, Aminu Kano Teaching Hospital, Kano, Nigeria

\begin{abstract}
Studies have shown that malaria contribute significantly to mortality among infants and children with Sickle Cell Anemia (SCA). The nomadic lifestyle of the Fulanis make access to health care difficult and exposure to malaria high. We conducted a cross sectional study among consenting members of a semi-nomadic Fulani population in Nigeria to determine the impact of malaria on the outcome of SCA. On-the-spot malaria rapid diagnostic test (RDT) and hemoglobin electrophoresis were done. A total of 229 subjects participated, 100 (43.7\%) females. Median age was 35 years (yrs) with range of 15-80 yrs. Hemoglobin AS phenotype was found among $53(23.1 \%)$ subjects; none had hemoglobin SS. A positive malaria RDT was found among $24(10.5 \%)$ individuals The FGD revealed that majority of the respondents considered malaria as an important cause of ill-health but were not aware of SCA as an important disease. The high prevalences of malaria, hemoglobin AS phenotype, and absent of hemoglobin SS in the community implies the potentially fatal effect of malaria on individuals with hemoglobin SS. A comprehensive intervention to reach this vulnerable population is thus recommended.
\end{abstract}

\section{Introduction}

Malaria is an important cause of morbidity and mortality in sub-Saharan Africa (SSA) and Nigeria has failed to reach the 1998 Abuja Roll Back Malaria (RBM) declaration targets. ${ }^{1}$ The very young, the pregnant and those with chronic hemolytic anemias notably sickle cell anemia (SCA) are among the worst affected by malaria. The close geographic association between the distribution of malaria and sickle cell gene in Africa provides an insightful association. Having the birth of 230,000 children annu- ally with SCA, Nigeria accounts for approximately $80 \%$ of the global burden. ${ }^{2}$ Another report put the estimated birth at 300,000 with Nigeria accounting for roughly $40 \%$ of all SCA births. ${ }^{3}$ More than $50 \%$ of these children die annually, with malaria making a major contribution in African children. ${ }^{4-6}$

Earlier works in Nigeria revealed a prevalence of $21-25 \%$ for sickle cell trait and $1-3 \%$ for SCA. ${ }^{7}$ The mechanism for the survival advantage in malaria of hemoglobin AS phenotype (HbAS) compared with hemoglobin AA phenotype (HbAA) and SCA (HbSS) as explained by the law of balanced polymorphism remained poorly understood. Possible explanations include selective sickling and removal of parasitized RBCs by the reticulo-endothelial system, inhibition of parasite growth by the greater potassium loss and low $\mathrm{pH}$ of the sickled red cells, greater endothelial adherence of parasitized red cells, reduced ability of Plasmodium falciparum parasites to grow and multiply in HbAS erythrocytes as well as accelerated acquisition of malariaspecific immunity. 8,9 On the other hand, HbSS individuals are at increased lifethreatening crises and increased susceptibility to infections because of hyposplenism, inadequate opsonization and diminished cell mediated immunity. ${ }^{10}$ This is further buttressed by the fact that daily oral penicillin prophylaxis reduces the risk of pneumococcal infections in children with SCA. ${ }^{11}$ Furthermore, some local studies have shown the contribution of malaria to mortality in infants and children with SCA and the value of prophylaxis and other quality of care measures in reducing same. ${ }^{12,13}$ Thus, in rural Nigeria, where malaria is endemic, infections common, and access to qualitative health care is sub-optimal, $\mathrm{HbSS}$ individuals hardly live to adult age.

The Fulanis in northern-Nigeria have cattle rearing and farming as their major occupation. Thus, they contribute significantly to meat and milk production. Regardless of whether they are fully nomadic or semi-nomadic, their settlement in a malaria endemic area and the practice of polygamy and consanguineous marriage could result in high incidence of malaria and SCA respectively. This is because genetic diseases with recessive modes of inheritance have shown higher predilection to consanguineous marriages ${ }^{14,15}$ and it has been reported that consanguineous marriages and polygamy tend to be the prevailing predisposing epidemiological factors in the transmission of SCA. ${ }^{16}$

Through landmark projects in developed countries, the common causes of morbidity and mortality in children with SCA
Correspondence: Baffa A. Gwaram, Bayero University, Aminu Kano Teaching Hospital, Kano, Nigeria.

E-mail: baffagwaram@npmcn.edu.ng

Key words: malaria; sickle cell anemia; nomadic population.

Acknowledgements: We wish to acknowledge the support of the Local Government council, the District Head and council of traditional rulers of Rano town in Kano state, Nigeria.

Contributions: $\mathrm{BAG}, \mathrm{MMD}$, concept, data collection, data analysis, article writing, article review; MH, ZGH, MMB, AMY, KMK, concept, data collection, article review; AHS, HA, ZGV, data collection, article review; FSF, concept, data collection; AGH, concept, article review.

Conflict of interest: the authors declare no potential conflict of interest.

Funding: none.

Received for publication: 27 August 2018.

Revision received: 18 October 2018

Accepted for publication: 18 October 2018.

This work is licensed under a Creative Commons Attribution NonCommercial 4.0 License (CC BY-NC 4.0).

(C) Copyright B.A. Gwaram et al., 2018 Licensee PAGEPress, Italy

Pyramid Journal of Medicine 2018; 1:22 doi:10.4081/pjm.2018.22

have been well established. ${ }^{17}$ However, with the high burden of both malaria and SCA in Nigeria, surprisingly little research has been conducted to ascertain malaria is a major cause of death among children with SCA. Perhaps the old Garki project, conducted in North Western Nigeria during the 1970 s is the only study in this part of the country which provided some evidence of high mortality among SCA children attributable to malaria. ${ }^{18,19}$ Additionally, there are studies especially from East Africa that have suggested that malaria is not a major cause of death in children with SCA. ${ }^{20-22}$

There has been remarkable ecological and population dynamics changes since the publication of the Garki study in Kano state, thus this study aims to elucidate the current demographic dynamics and assess the impact of malaria incidence in the area. Furthermore, the Garki study was done among domesticated rural Hausa population, we thus aim to study a nomadic Fulani population. Determining the true association between malaria and mortality in SCA 
would provide strong justification for SCA newborn screening program and malaria prophylaxis. The nomadic lifestyle of the Fulanis exposes them more to malaria and at risk of being overlooked in micro-planning by national disease control programs, malaria inclusive. The dual combination of malaria and SCA in the setting of poor access to health care could lead to low survival rate among SCA infants and children.

\section{Materials and Methods}

\section{Study design}

Using a cross sectional study design, we conducted a community survey in a seminomadic Fulani setting in Kano state, North Western Nigeria to determine the burden and effect of malaria on outcomes of Sickle Cell Disease (SCD). During a community health outreach, a community survey was conducted to determine the incidence of Sickle Cell Disease (SCD) and malaria. Interviews were conducted with consenting adults that agree to provide blood samples for genotype, packed cell volume (PCV) and malaria rapid diagnostic tests (RDT). This was complemented by ethnographic methods (focus group discussions [FGD]) to identify perceived common illnesses and felt needs of the community.

Ethical approvals for this survey were obtained from the ethical committee of Aminu Kano Teaching Hospital (AKTH), Kano state Ministry of Health and Rano Local government Council of Kano state.

\section{Interviews}

We administered a structured questionnaire to consenting individuals 15 years and above to obtain information on age, gender, income, marital status, consanguinity and symptoms of malaria. Further information was obtained to determine knowledge, attitude and preventive practices against malaria and SCA. A 12-month verbal autopsy was conducted to identify recognized causes of death within the community. Questionnaires were administered by staff of the Department of Medicine, AKTH Kano, Nigeria. They were trained for a period of two days to ensure uniformity and consistency of the collected data.

\section{Laboratory methods}

Three milliliters $(3 \mathrm{mls})$ of venous blood were collected from a prominent superficial arm vein of consenting participants using aseptic venepuncture technique. The blood sample was then carefully transferred into an EDTA container and mixed properly.

Hemoglobin phenotyping and (PCV) were performed by an experienced laboratory hematologist using the cellulose acetate electrophoresis at alkaline $\mathrm{pH}$ of 8.4-8.6 and the microhematocrit method respectively with appropriate controls as described in Dacie and Lewis. ${ }^{23}$

On-the-spot malaria rapid diagnostic test (RDT) was conducted using SD-bioline RDT kit. The test was conducted by an experienced laboratory technologist in conformity with the manufacturer's instructions.

\section{Qualitative methods}

FGDs were conducted with selected members of the community to determine knowledge, attitude and preventive practices against malaria and SCA. Three FGDs were conducted: young men (15-44 yrs), middle-elderly aged (45 above yrs), and women of reproductive age (15-45 yrs). Each group had 15-20 participants and the sessions lasted 60-90 minutes. The FGD guide was developed using key thematic areas aimed at determining awareness of and preventive measures against development of common communicable and noncommunicable diseases. Each session was conducted by 2 interviewers with experience in conducting qualitative research. One of the interviewers moderated the interview while the other documented the proceedings. The data collected was grouped into various thematic areas to enable identification of the most recurrent themes.

\section{Data analysis}

Data was collated and entered by 2 individual clerks (double entry) to ensure accuracy and consistency. In the event there was disparity between the 2 entries the questionnaire was recalled for adjunction. We compared prevalence of malaria, consanguinity and hemoglobin phenotypes within the community. We summarized categorical data as proportions and continuous data were presented as median with inter quartile range. We compared proportions using the $\chi^{2}$ test or student's t test as appropriate. All analyses were conducted using STATA, Version 10.0. A P value of 0.05 or less is taken as statistically significant.

\section{Results}

A total of 229 subjects were interviewed of which100 (43.7\%) are females and 129 (56.3\%) males. Median age (Inter Quartile Range) was 35 yrs (25-50 yrs). Among the 194 married respondents, 100 (51.5\%) were in consanguineous marriages. More than two-thirds of the women $73(73.0 \%)$ were of reproductive age. Cattle rearing is the most common occupation among 71 (31\%) respondents. Symptoms of malaria and positive RDT were found among 97 (42.4\%) and $24(10.5 \%)$ subjects respectively. $\mathrm{Hb}$ AS was found among $53(23.1 \%)$ of the subjects; none had $\mathrm{Hb}$ SS (Table 1). The median PCV (Inter Quartile Range) was $36 \%$ (33-46\%). As shown in Table 2, a statistically significant relation was found between hemoglobin phenotype and age $(\mathrm{P}=0.01)$. However, no statistically significant relation was observed between hemoglobin phenotype and PCV $(\mathrm{P}=0.35)$; Malaria symptoms $(\mathrm{P}=0.89) ; \quad \mathrm{RDT}$ $(\mathrm{P}=0.31)$; gender $(\mathrm{P}=0.51)$; occupation $(\mathrm{P}=0.32)$; marital status $(\mathrm{P}=0.34)$; consanguinity $(\mathrm{P}=0.65)$; and family history of SCD $(\mathrm{P}=0.71)$. Similarly, no relation was found when RDT and PCV were compared $(\mathrm{P}=0.58)$.

Table 3 shows that among those with positive RDT, $13(54.2 \%)$ were women of reproductive age.

Perceived causes of death among respondents based on 12 months verbal autopsy revealed that of 90 respondents that lost a relation within their household, 36 (40\%) were as a result of an infectious cause. A similar proportion [37 (41\%)]

Table 1. Socio-demographic, clinical and diagnostic parameters of study subjects ( $\mathrm{N}=229)$.

\begin{tabular}{lc} 
Characteristic & N. of Patients (\%) \\
Female Sex & $100(43.7)$ \\
Median age (range)(yrs) & $36.5(15.0-80.0)$ \\
\hline Occupation & \\
Farming & $142(62.0)$ \\
Cattle rearing & $71(31.0)$ \\
Others & $16(7.0)$ \\
Marital status & $194(84.7)$ \\
Married & $19(8.3)$ \\
Single & $14(6.1)$ \\
Widowed & $2(0.9)$ \\
Divorced & \\
\hline Marriage type & $100(51.5)$ \\
Consanguineous & $94(48.5)$ \\
Non-consanguineous & \\
Malaria symptoms & $156(97.5)$ \\
Present & $4(2.5)$ \\
Absent & \\
\hline Malaria RDT & $24(10.5)$ \\
RDT positive & $205(89.5)$ \\
RDT negative & $36(33-40)$ \\
Median PCV (IQR) & \\
\hline Hb electrophoresis & $176(76.9)$ \\
AA & $53(23.1)$ \\
AS & $0(0.0)$ \\
Others (SS, AC) & \\
\hline
\end{tabular}

$\mathrm{AA}=$ Hemoglobin $\mathrm{AA}, \mathrm{AC}=$ Hemoglobin $\mathrm{AC}, \mathrm{AS}=$ Hemoglobin $\mathrm{AS}, \mathrm{SS}=$ Hemoglobin $\mathrm{SS}, \mathrm{Hb}=$ Hemoglobin, $\mathrm{IQR}=$ inter quartile range, $\mathrm{RDT}=$ rapid detection test. 
where due to other non-communicable diswere due to either recognized chronic noninfectious diseases or sudden, unexplained deaths. Only one death was due to a known case of SCA (Table 4).

\section{FGD}

The FGD revealed that respondents considered malaria an important cause of ill-health but lack knowledge of appropriate preventive measures against it. None of the participants was aware of SCA as a disease not to talk of how to prevent it. Majority of eases; more than half of which [24 (26.6\%)]

the participants consider potable water supply, access roads and a health care facility as their felt needs in order of priority. According to a $24 \mathrm{yr}$ old mother of two: Mosquitoes are a major problem for us. They disturb our sleep and cause 'janta' (fever). We simply close our doors early in the evening to reduce the number that enter our rooms. An elderly man who never heard of SCA responded thus: We don't know any disease like that. I don't believe marriage to a close relation (consanguinity) causes any disease. Just provide us with water, roads, and health center and God will bless you. A teenager had a different perspective: I am

Table 2. Comparison of bio-demographic/ laboratory findings and hemoglobin phenotype.

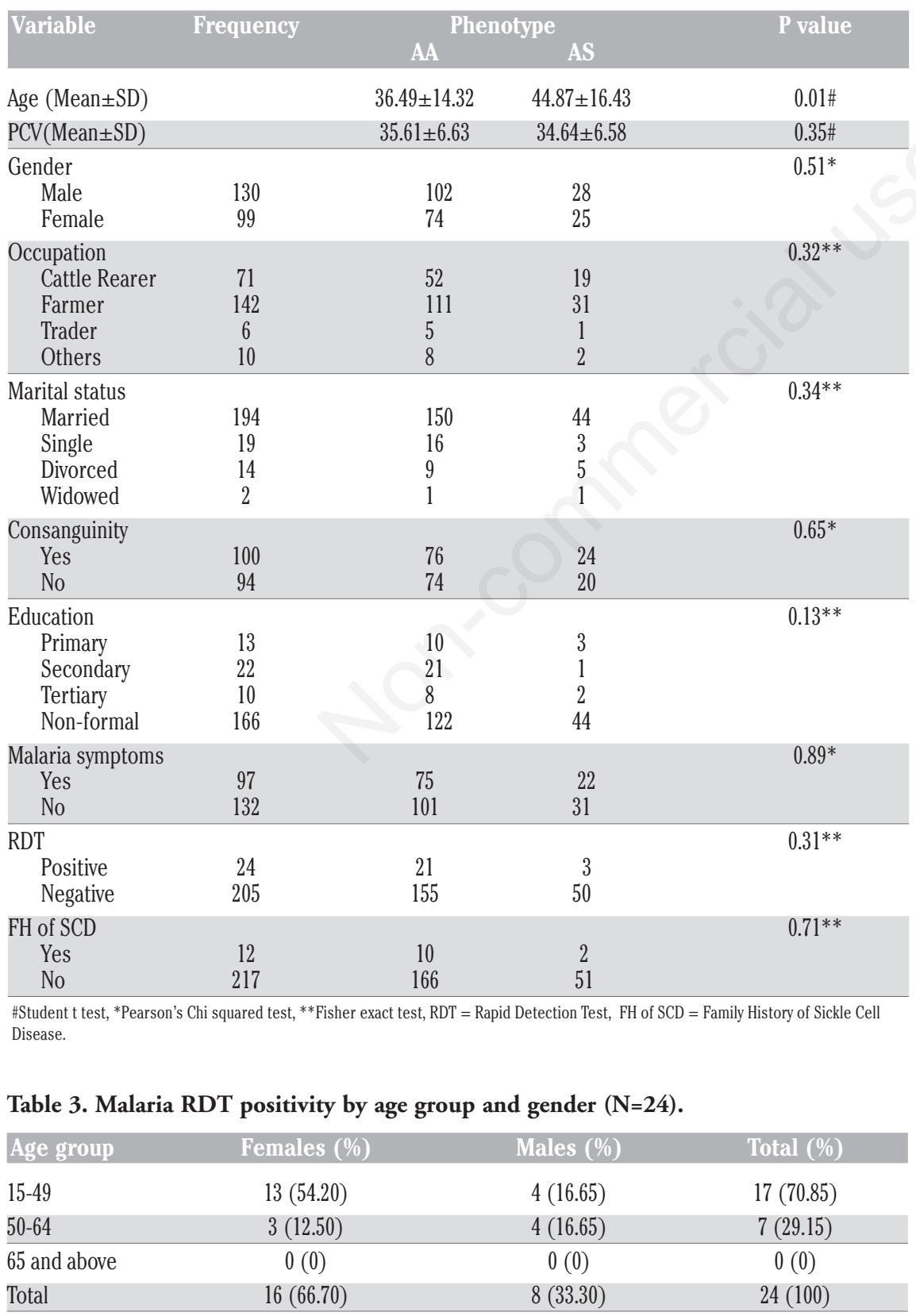

married to my cousin for 5 years and we are fine. We have three children and lost only one at the age of two. We don't think our being close relations have anything to do with this. My main concern is how to take care of my family. Get a borehole for us and we are fine",

\section{Discussion}

Our study reveals the absence of HbSS among adults in this semi nomadic population despite high number of $\mathrm{HbAS}$ and more than $50 \%$ of the married individuals engaged in consanguineous marriages. In the setting of the high prevalence of malarial symptoms and $10.5 \%$ RDT positivity found in this study population, this may suggest the effect of natural selection by common infections especially malaria preventing the survival of individuals with $\mathrm{HbSS}$ and at the same time protecting $\mathrm{HbAS}$ in the population. This is because in HbAS, Plasmodium falciparum-infected red cells sickle preferentially and get eliminated from the circulation by macrophages. ${ }^{24}$ Also, symptomatic malaria infection is prevalent in individuals with sickle cell traits which confirms the protection of this genetic disorder against severe malaria. ${ }^{25}$ Conversely, HbSS individuals are highly susceptible to the lethal effects of malaria because malaria worsens the anemia of SCA and is a major trigger of crises. Hyposplenism which is a positive adaptation in SCA also reduces parasite clearance. ${ }^{19}$ Though there was no statistically significant relation established in this study between phenotypes and symptoms of malaria and also with RDT, these mechanisms may partly explain our finding of a statistically significant difference in age in the study population $(\mathrm{P}=0.01)$ with $\mathrm{HbAS}$ individuals having a higher mean age of

Table 4. Distribution of common causes of death based on verbal autopsy $(\mathrm{N}=90)$.

\begin{tabular}{lc} 
Cause of death & Frequency (\%) \\
Childbirth (maternal) & $5(5.6)$ \\
SCA & $1(1.1)$ \\
\hline Chronic non-infectious diseases & $11(12.2)$ \\
Sudden death & $13(14.4)$ \\
\hline Cancers & $4(4.4)$ \\
Injuries/accidents & $5(5.6)$ \\
\hline Infectious diseases & $36(40.0)$ \\
Neonatal/infant mortality & $7(7.8)$ \\
\hline Unclear cause & $8(8.9)$ \\
Total & $90(100)$ \\
\hline
\end{tabular}


$44.89 \pm 16.43$ years compared to HbAA with an average age of $36.49 \pm 14.32$ years.

Thus, it is reasonable to hypothesize that $\mathrm{HbSS}$ adult could not be found in the community because the children die before reaching adulthood due to rudimentary health services that will ensure their protection against malaria and other common infectious diseases highly prevalent in the area. Our findings reflect those of the Garki project wherein less than $2 \%$ of those with SCA survived beyond the age of 4 years. ${ }^{19}$ The study provides the crude mortality from SCD in settings without health interventions. However, in a different report of the same study it was concluded that malaria infection in HbSS is less intense but more lethal than in HbAS and HbAA and antimalarial intervention did not lead to a significant decrease in $\mathrm{HbSS}$ mortality. ${ }^{18}$ Many other recent studies are suggesting that malaria is not a major cause of mortality among children with SCA. ${ }^{20-22}$ In contrast, a survival of $75 \%$ among $\mathrm{HbSS}$ at the age of 5 years from Kenya showed how much could be achieved with appropriate interventions. ${ }^{26}$ Also in the Cooperative Study of Sickle Cell Disease (CSSCD), approximately 85 percent of children and adolescents with SCA survived up to 20 years of age which was attributed to an integrated clinical approach to the management of SCA. ${ }^{27}$ Additionally a study by Kudnik et al. established the cost effectiveness of early screening plus administration of prophylactic interventions like use of Insecticide Treated Nets (ITN) in SCD in SSA. ${ }^{28}$ Thus, a cost-effective approach to malaria control which has been reported can be achieved by providing appropriate prevention and treatment for malaria to these neglected communities. ${ }^{29}$

The finding that majority of those with malaria RDT positivity were women of reproductive age is worrisome given the risk associated with malaria in pregnancy in terms of poor outcomes and congenital malaria. It implies poor availability, accessibility or utilization of ante-natal care services among nomads. This further support the findings of the FGD establishing lack of access to preventive and curative care as a major problem among nomads. There should be customized approach by disease control programs to addressing challenges faced by nomads. This has been shown to be useful in other programs like the National Stop Transmission of Poliomyelitis (NSTOP), nomadic education, and tuberculosis control programs, among others. ${ }^{30}$

Considering the advances made in management of SCD, malaria, and other infectious diseases, it is baffling to see existence of communities that were so underserved to the extent that their mortality from SCD is similar to that documented in past studies. ${ }^{6,19}$ Access to basic health care to this community is thus a matter of equity. In fact, high quality of care to SCD patients require the establishment and integration into the sickle cell comprehensive clinics that encompasses vaccinations, prophylactic therapy, nutritional and social support. This will ensure that in addition to providing care for common infections, better health maintenance could prevent frequent crisis thereby reducing the need for frequent transfusion that exposes Africans with sickle cell disease to HIV/AIDS, another common cause of mortality among Africans.

The finding of low level of awareness about prevention and treatment of malaria is similar to Akogun et al. 's studies of febrile illness in similar settings of Northern Nigeria in which he was able to show in a separate study, the cost-effectiveness and acceptability of the feverkit, a solar-powered device programmed with user-interactive capabilities that guide Nomads to distinguish malaria from non-malaria-induced fevers thereby selectively treating them. ${ }^{31}$ This and other universally accepted conventions like the home treatment of malaria, use of ITN, and indoor residual spraying under the Roll Back Malaria (RBM) initiative could go a long way in providing more access to care for malaria and other infectious diseases.

The high prevalence of malaria in our study subjects was unlikely to have been affected by the timing of the study given that it was conducted in an area of stable malaria transmission. Thus, the results are not likely to change if the study was conducted at other times of the year.

Our study is limited by the fact that it wasn't a longitudinal study and as such, a clear cause-effect could only be extrapolated. However, the similarities of our findings with previously conducted longitudinal studies means more attention should be paid to this neglected population with lack of access to basic amenities and proven health interventions.

\section{Conclusions}

Lack of access to basic health care still expose vulnerable populations like the nomads to the devastating effects of malaria and SCA. Furthermore, despite the high prevalence of AS heterozygotes in our setting, the people most affected lack the basic awareness of SCD and how to prevent or access care for it which needs to be addressed with more awareness campaigns.
Disease control programs should have customized approaches to special populations like the nomads in program planning and implementation. Further studies should be conducted to evaluate the efficacy and utility of other proven initiatives like the seasonal malaria chemoprevention (SMC), daily oral penicillin and pneumococcal conjugate vaccines use in SCA in special populations like the nomads.

\section{References}

1. Orimadegun AE, Fawole O, Okereke $\mathrm{JO}$, et al. Increasing burden of childhood severe malaria in a Nigerian tertiary hospital: implication for control. J Trop Pediatr 2007;53:185-9.

2. Modell B, Darlison M. Global epidemiology of haemoglobin disorders and derived service indicators. Bull WHO 2008;86:480-7.

3. Piel FB, Hay SI, Gupta S, et al. Global burden of sickle cell anaemia in children under five, 2010-2050: modelling based on demographics, excess mortality, and interventions. PLoS Med 2013; 10:e1001484

4. Weatherall D, Akinyanju O, Fucharoen $\mathrm{S}$, et al. Inherited Disorders of Hemoglobin. In: Jamison DT, Breman JG, Measham AR, et al., (eds.). Disease Control Priorities in Developing Countries. 2nd ed. Washington (DC) 2006.

5. Williams TN, Obaro SK. Sickle cell disease and malaria morbidity: a tale with two tails. Trends Parasitol 2011;27:31520.

6. Serjeant GR. Mortality from sickle cell disease in Africa. BMJ 2005;330:432-3.

7. Akinyanju OO. A profile of sickle cell disease in Nigeria. Ann NY Acad Sci 1989;565:126-36.

8. Williams TN, Mwangi TW, Roberts DJ, et al. An immune basis for malaria protection by the sickle cell trait. PLoS Med 2005;2:e128.

9. Williams TN, Mwangi TW, Wambua S, et al. Sickle cell trait and the risk of Plasmodium falciparum malaria and other childhood diseases. J Infect Dis 2005;192:178-86.

10. Parry E. Principles of Medicine in Africa. 4th ed. Cambridge University Press, 2013, p.928.

11. Gwaram HA, Gwaram BA. A systematic review of effectiveness of daily oral penicillin $\mathrm{v}$ prophylaxis in the prevention of pneumococcal infection in children with sickle cell anaemia. Nig J Med 2014;23:118-29.

12. Ibidapo MO, Akinyanju OO. Acute 
sickle cell syndromes in Nigerian adults. Clin Lab Haematol 2000;22:151-5.

13. Akinyanju OO, Otaigbe AI, Ibidapo MO. Outcome of holistic care in Nigerian patients with sickle cell anaemia. Clin Lab Haematol 2005;27:195-9.

14. Bittles A. Consanguinity and its relevance to clinical genetics. Clin Genet 2001;60:89-98.

15. Shawky RM, Elsayed SM, Zaki ME, et al. Consanguinity and its relevance to clinical genetics. Egypt J Med Hum Genet 2013;14:157-64.

16. Cameron BF. Sickle cell anaemia transmission. Blood 1983;58:180-186

17. Gill FM, Sleeper LA, Weiner SJ, et al. Cooperative study of sickle cell disease. Chest 1995;108:1214-9.

18. Molineux L, Fleming AF, ComileBlogger R, et al. Abnormal haemoglobins in Sudan Savanna of Nigeria III. Malaria immunoglobulins and antimalarial antibodies in sickle cell disease. Ann Trop Med Parasitol 1979;73:301-10.

19. Fleming AF, Storey J, Molineaux L, et al. Abnormal haemoglobins in the Sudan savanna of Nigeria. I. Prevalence of haemoglobins and relationships between sickle cell trait, malaria and survival. Ann Trop Med Parasitol 1979;73:161-72.

20. McAuley CF, Webb C, Makani J, et al. High mortality from plasmodium falciparum malaria in children living with SCA on the coast of Kenya. Blood 2010;116:1663-8.

21. Makani J, Komba A, Cox S, et al. Malaria in SCD: Differences in burden, risk factors and outcome between patients at outpatient clinic and during hospitalization. Blood 2010;115:21520.

22. Komba AN, Makani J, Sadarangani M, et al. malaria as a cause of morbidity and mortality in children with homozygous SCD on the coast of Kenya. Clin Infect Dis 2009;49:216-22.

23. Bain BJ, Lewis MS, Bates I. Basic hematological techniques. In: SM Lewis (ed). Dacie and Lewis Practical Haematology. 10th Ed. Churchill Livingstone Publishers 2007. pp 282284.

24. Luzzatto L, Nwachuku-Jarrett ES, Reddy S. Increased sickling of parasitised erythrocytes as mechanism of resistance against malaria in the sicklecell trait. Lancet 1970;1:319-21.

25. Kamugisha E, Manyama M, Rambau P, et al. Prevalence of sickle cell, malaria and glucose-6-phosphate dehydroge- nase deficiency among primary school children in Nyamagana District, Mwanza-Tanzania. Tanzania Med J 2011;25:1.

26. Aidoo M, Terlouw DJ, Kolczak MS, et al. Protective effects of the sickle cell gene against malaria morbidity and mortality. Lancet 2002;359:1311-2.

27. Gill FM, Sleeper LA, Weiner SJ, et al. Cooperative study of sickle cell disease. Chest 1995;108:1214-9.

28. Kuznik A, Habib AG, Munube D, Lamorde M. Newborn screening and prophylactic interventions for sickle cell disease in 47 countries in subSaharan Africa: a cost-effectiveness analysis. BMC Health Serv Res 2016;16:304

29. Fleming AF. Cost-effectiveness of malaria control in sub-Saharan Africa. Lancet 1999;354:1123.

30. John S, Gidado M, Dahiru T, et al. Tuberculosis among nomads in Adamawa, Nigeria: outcomes from two years of active case finding. Int $\mathrm{J}$ Tuberc Lung Dis 2015;19:463-8.

31. Akogun OB, Gundiri MA, Badaki JA, et al. Febrile illness experience among Nigerian nomads. Int $\mathrm{J}$ Equity Health 2012;11:5. 